Lisbon - Malacca Port Cities Twin Conferences 2019 / 2020

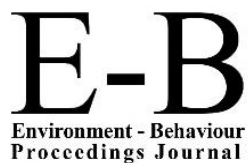

AicQoL2020Malacca

ASLI (Annual Serial Landmark International) Conferences on QoL2020

https://www.amerabra.org; https://fspu.uitm.edu.my/cebs; https://www.emasemasresources.com/

8th AMER International Conference on Quality of Life

Mahkota Hotel Melaka, Malacca, Malaysia, 18-19 Mar 2020

(Due to the Covid-19 lockdown, paper virtually presented on 25 Mar 2020)

\title{
Humanizing Technology: Smartphone usage in the learning environment
}

\author{
Mohd Zdikri Md Sabron 1, Rugayah Hashim 2 , Aida Abdullah ${ }^{1}$, Nurshamshida Shamsudin ${ }^{3}$ \\ 1 Faculty of Administrative Science \& Policy Studies, \\ Universiti Teknologi MARA, Shah Alam, Malaysia \\ 2 Research \& Innovation Division \\ 3 Faculty of Education, \\ Universiti Teknologi MARA, Selangor Branch, Puncak Alam Campus, Malaysia
}

zdikri82@gmail.com; guy73106@yahoo.com,abdullah_aida45@yahoo.com,nurshamshida@gmail.com

Tel. 013-2384153

\begin{abstract}
The objective of this paper is to determine the influence of smartphone usage among secondary school students. The sample size of the study was 150 students. The findings showed that smartphone usage increases compassionate teaching with significant student engagement through the enhancement of the learner's cognitive capacity, motivation to study in both formal and informal settings, autonomy and confidence, as well as the promotion of personalized learning in helping low-achieving students to reach their academic performance goals. The implications verified that implementing smartphone usage in the classroom will result in an effective and proper process in the learning environment.
\end{abstract}

Keywords: Humanizing technology; Smartphone Usage; Learning Environment; Student Engagement

eISSN: 2398-4287 @ 2020. The Authors. Published for AMER ABRA cE-Bs by e-International Publishing House, Ltd., UK. This is an open access article under the CC BYNC-ND license (http://creativecommons.org/licenses/by-nc-nd/4.0/). Peer-review under responsibility of AMER (Association of Malaysian Environment-Behaviour Researchers), ABRA (Association of Behavioural Researchers on Asians) and cE-Bs (Centre for Environment-Behaviour Studies), Faculty of Architecture, Planning \& Surveying, Universiti Teknologi MARA, Malaysia.

DOI: https://doi.org/10.21834/e-bpj.v5i13.1958

\subsection{Introduction}

The role of humanizing technology plays in human life is turning into an undeniably earnest inquiry (Rowsell et al., 2016). Undoubtedly, today's humanizing technology has become part of human life. The development of technology, especially the smartphone, is increasing in consumerism regardless of age, race, or gender (Sundus, 2017). The function of the Smartphone is to provide social media mediums to be achieved by its users easily (Haug et al., 2015). Also, new technologies nominated from the smartphone preferred many apps that people use in order to get the word out, and people think these tools are empowering people in the world to help make revolutions happen and help such things to be better. In the era of this unlimited telecommunications and multimedia technology revolution, the smartphone is widely used among the people (Alhassan et al., 2018). It is not an uncommon sight to watch students' working with smartphones nowadays. The usage of e-learning, also known as a web-based learning system, has been growing steadily during the last two decades (Tarhini, Hone, \& Liu, 2015). The scholars revealed that this growth is due to the increased competition among educational institutions in order to attract students and meet their educational needs and goals. However, the studies have indicated that web-based learning is not just an innovative arrangement yet additionally a procedure of various variables, such as social factors, for example, authoritative factor for encouraging conditions and individual factors including the adequacy of personal computers, behavior and cultural factors (Kumi Yeboah \& Smith, 2016). The need to comprehend the acknowledgment and selection of technology by students with regards to creating and created nations features the significance of researching the variables that impact the students' acceptance of the technology (Fernandez-Montalvo, Penalva, \& Irazabal, 2015). In short, the use of smartphones among students can

eISSN: 2398-4287 @ 2020. The Authors. Published for AMER ABRA cE-Bs by e-International Publishing House, Ltd., UK. This is an open access article under the CC BYNC-ND license (http://creativecommons.org/licenses/by-nc-nd/4.0/). Peer-review under responsibility of AMER (Association of Malaysian Environment-Behaviour Researchers), ABRA (Association of Behavioural Researchers on Asians) and cE-Bs (Centre for Environment-Behaviour Studies), Faculty of Architecture, Planning \& Surveying, Universiti Teknologi MARA, Malaysia.

DOI: https://doi.org/10.21834/e-bpj.v5i13.1958 
facilitate their learning affairs. This study aims to determine the influence of smartphone usage in the learning environment among secondary school students in Malaysia. Therefore, good comprehension, a study needs to be implemented to answer the objective and the findings that contribute to new knowledge and guidelines in the field of academics in administrative science and policy studies, government, ministry, policymakers, society, parents, and students. Thus, this paper concentrate on three main objectives:

1.1 To examine the behavioral responses on smartphone usage among students.

1.2 To examine the significant relationship between Smartphone Usage in the Learning Environment.

1.3 To examine the relationship between smartphone usage and students' behavioral capability through the mediating effect of the learning environment.

\subsection{Literature Review}

Previous studies in the usage of technology as learning platform show significant impact such as improvements of learning engagements, increase students motivations, reduce students' anxiety in language learning and technology serve fun learning platform rather than the traditional classroom (Kumi Yeboah \& Smith, 2016; Redmond, Heffernan, Abawi, Brown, \& Henderson, 2018; Yeh et al., 2019). Furthermore, the study on smartphone usage in the classroom is overwhelming over the years. Due to the influx number of smartphone learning and entertainment application, it shows that smartphone is the best learning tools for students (Rizki, Supriyati, \& Akbar, 2020). The smartphone is additionally connected in education either as an understudy or a teacher (Kacetl \& Klimova, 2019; Aljaloud, Billingsley, \& Kwan, 2019). The scholars state that smartphones utilize them as a showing apparatus, strategies, and instrument to spread data quickly and effectively. While on the understudy point of view, smartphone usage undoubtedly provides significant assistance at assembling data directly at the tips of their fingers (Samaha \& Hawi, 2016). Students are presented with various methods for learning through the internet (Lara \& Magraner, 2017). The Scholars state that students can get to a ton of assortment of data inside a brief timeframe anyplace and whenever making learning significantly simpler. Additionally, the use of ICT and gamification in the classroom improved students' motivation and learning, especially those who were less motivated. The direct relation between the students' seats in the classroom and their motivation was verified. At the same time, the learning differences between all the students in the classroom were reduced, hence achieving a balance between the learning and the motivation of the students. For example, it sets aside such a considerable amount of time recorded as a hard copy by looking at composing an article on a paper and making one utilizing the word application. Composing on paper is tiring, even a solitary word may take up 3 seconds of the time while on the console its solitary like 1.5 seconds. Another best thing would be how helpful word application is for featuring incorrect spellings, however, on paper, we need to edit, even with odds of missing the wrong spellings which equivalents to losing marks (Anshari \& Alas, 2015). Smartphones can be utilized as account addresses, which helps in educational instructing and learning as in introductions or addresses can be recorded utilizing a video recorder (Razzaq, Samiha, \& Anshari, 2018). The recorded addresses would then be able to be utilized as a students' direction just as a reference for their assignments or homework. What the study can uncover that the outcomes students invest more energy on the Internet through a cell phone. Students additionally will, in general, be the further developed users of smartphones (Anshari et al., 2017). Such learning supported with mobile devices is called mobile learning, which seems beneficial mainly thanks to the unique features of mobile applications (e.g., interactivity, ubiquity, and portability) and teachers' encouragement and feedback (Kacetl \& Klimova, 2019).

\subsection{The Impact of Smartphone on Student}

The students who use the smartphone in positive ways to organize and maintain their social networks Cha \& Seo (2018). Numerous examinations, for example, H. Lee, Kim, \& Choi, 2017; Razzaq, Samiha, \& Anshari, 2018; Yeh et al., 2019) have been led to surveying the utilization and impacts of smartphones particularly for learning purposes. For instance, Anshari et al. (2017) investigated the idea of undergraduates' utilization of smartphones. The young adults' perceptions of smartphones are mainly for social communication and not just for educational use. Chan, Walker, and Gleaves (2015), Ramadiani, Azainil, Haryaka, Agus, and Kridalaksana (2017) revealed that smartphones have contrary consequences for a learning procedure. In spite of there has been various research take a shot at how smartphones are being utilized in advanced education, the extraordinary spotlight was given on understudy's points of view $\mathrm{H}$. Lee, Kim, \& Choi, 2017; Ramadiani, Azainil, Haryaka, Agus, \& Kridalaksana, 2017; Razzaq, Samiha, \& Anshari, 2018). The training was applied on how to implement the smartphone clicker app effectively in lesson activities is a significant influence on teachers' perceptions of the usefulness of, and their decision to use, the app (Aljaloud et al., 2019). The scholars revealed that the main implication of the findings is that smartphone clicker app developers and user training coordinators must consider teachers' perceptions of the suitability of the technology and their desire to design learning tasks to facilitate student participation and engagement.

\subsection{Technology and behavior}

The utilization of e-learning or online learning has been growing reliably during the latest two decades (Kırcaburun et al., 2019). This advancement is a result of the extended test among high enlightening establishments in order to pull in understudies and meet their educational needs and targets. Also, online learning can assist with both face-to-face and remote course transport without the necessities of time and detachment (Redmond et al., 2018). The scholars revealed that the framework was developed by considering the essentials for impactful online learning. The essentials are behavioral engagement, including developing academic skills, identifying opportunities and challenges, developing multidisciplinary skills, developing agency, upholding online learning norms, and supporting and encouraging peers. Furthermore, learning and teaching online is complex, and the study continues to learn how to support the online learning journeys of students more effectively. Besides that, the Information and Communication Technologies (ICT) have 
experienced rapid technological progress that has resulted in new forms of social relations and new channels of transmission of information (Lara \& Magraner, 2017). The scholars revealed that these changes modified the behavior of all age-groups. However, the main impact has been on the most recent generations, where the use of ICT areas daily as any other necessary activities of the day. These new generations have grown up in a digital and interconnected environment, and they respond to stimuli and interests in different ways compared to previous generations (Tarhini et al., 2015; Fajriyah \& Fauziyah, 2018). The online learning framework is to be viewed as successful if it can replicate the classroom experience and consider the students' needs. If the students do not utilize the framework, at that point, its advantages will not be wholly used (Tarhini et al., 2015). Razzaq et al. (2018) revealed that the primary intention of mobile learning is for more accessibility, particularly in long-distance learning with friends, teachers, and even communities. Additionally, access to the Internet has never been easier and the vast amount of information is just at the tip of our fingers. Furthermore, there are mobile learning applications for almost supporting all modules of distance learning activities. Besides communication, smartphones in mobile learning can also function as a video recorder to record lectures (Razzaq et al. (2018). The original TAM model, the behavioral intention, was affected by two perceived factors, namely, perceived ease of use and perceived usefulness, and the former also significantly affected the latter (Chen \& Liu, 2017). The scholars revealed that the study replaced the original perceived variables in the TAM with perceived system use, mainly to evaluate the overall perception of e-learning system usage. Additionally, the system usage referred to in this study comes partially from the use of hardware equipment.

\subsection{Factors Associated with the environment including Technology}

The proposed model achieves acceptable fit and explains for $69 \%$ of the British sample and $57 \%$ of the Lebanese sample of its variance, which is higher than that of the original TAM model (Tarhini et al., 2015). Furthermore, the findings suggest that individual, social, and organizational factors are important to consider in explaining students' behavior intention (BI) and usage of e-learning environments. Additionally, in this context, all the major and different individual factors should be considered simultaneously because only then a complete picture of the dynamic nature of individual technology may begin to emerge. A total of $98 \%(65)$ of interview participants said they use technology in their youth programming; 69\% (18) of focus group participants mentioned using technology in their youth programming. Many youth-serving librarians use technology in ways that align with connected learning (Bussell, 2019). Furthermore, youth-serving library workers are successful in finding community partners to help plan technology-enabled programming. They strive to develop connected learning programs based on the interests of their youth patrons, and they often take on the role of "media mentor" by exploring technology collaboratively with their patrons. Additionally, youth-serving library workers face several challenges in implementing connected learning. These include difficulties with openly networked infrastructures, struggling to create learning environments that align with the hanging out, messing around, and geeking out (HOMAGO) stages of connected learning, and lack of confidence and experience in mentoring youth patrons on how to use technology (Bussell, 2019).

\subsection{Smartphone in a learning environment}

The mobile learning is becoming a salient feature of education as it is an excellent opportunity for foreign language learning (Kacetl \& Klimova, 2019). Furthermore, its key benefits are as follows: the enhancement of the learner's cognitive capacity, the learner's motivation to study in both formal and informal settings, the learner's autonomy and confidence, as well as the promotion of personalized learning, helping low-achieving students to reach their study goals. Additionally, although mobile learning seems to be effective overall, it is desirable to design, plan and implement it with caution, according to students' needs, and to deliver multiple language skills in authentic learning environments. There was evidence that several individual instructional characteristic components influence students' learning, satisfaction, and academic performance in online courses (Joosten, Cusatis, \& Harness, 2019; Alghamdi, Karpinski, Lepp, \& Barkley, 2020). The scholars revealed that the instrument developed from this research regarding the quality of learning in online formats predicts students' learning, satisfaction, and academic performance. Furthermore, the individual constructs provide more details as to what areas of course structure may be influencing student outcomes as well as implications for practice. The provision of Internet-enabled technologies and professional development as actions to support competent and confident inclusion of Web-searching in classrooms (Thorpe et al., 2015). Furthermore, actions are necessary to align with national policy documents that define the acquisition of digital literacies as a goal and assert digital access to knowledge as an issue of equity. Bryant et al. (2015) state that instructional applications (apps) are educational software programs that can be accessed via mobile technologies (e.g., iPad, smartphone) and used to help students acquire various academic skills, including mathematics. Although research suggests that app-based instruction (Al) can be useful, there is a paucity of research comparing Al to teacher-directed instruction (TDI) or a combination of instructional approaches (CI) involving both $\mathrm{Al}$ and TDI in tandem. In an alternating treatment design, we compared $\mathrm{Al}, \mathrm{TDI}$, and $\mathrm{Cl}$ conditions during instruction targeting multiplication facts with six students with learning disabilities (Bryant et al., 2015).

\subsection{Smartphone and academic performance}

The widespread of humanizing technology contains a profound impact on the tutorial lives of the school students these days (Arefin et al., 2017). Furthermore, smartphone usage became widespread to the young generation, especially school students owing to its academic and diverting choices by mistreatment the many applications. Among school students, students are progressively victimization smartphones. However, excessive smartphone usage sometimes makes the scholars obsessed with it, which impacts on user's educational performance, daily activities, physical and mental state, withdrawal tendency, and social relationships. Samaha and Hawi (2016) revealed that smartphone addiction risk was positively related to perceived stress, but the latter was negatively related to satisfaction with life. Additionally, a smartphone addiction risk was negatively related to academic performance, but the latter was positively related to satisfaction with life. Furthermore, there was a zero-order correlation between smartphone addiction and satisfaction 
with life on one hand and between perceived stress and academic performance on the other hand. As smartphone use continues to be on the rise despite all the alarming negative implications mainly behavioral addiction, intervention programs must be developed and implemented without further ado with the most vulnerable population segments children and adolescents (Samaha \& Hawi, 2016). There are points of a smartphone in helping students to improve their confidence and understanding of mobile learning not only from because of internal factors but also external forces (Razzaq et al., 2018). Furthermore, whenever students participate in mobile learning, they will interpret their performance accomplishments and experiences to develop beliefs about their ability to engage in similar activities. While similar activities are bounded with smartphone habits and internet literacy level. If these activities are consistently successful, they tend to raise self-efficacy or, conversely, if these activities produce failure, then it leads to low self-efficacy (Razzaq et al., 2018).

\subsection{Conceptual Framework}

This study applied the conceptual framework to give more understandings of humanizing technology and its effect on school students in Malaysia (see Fig. 1). Albert Bandura developed the social cognitive theory, and his theory was based on the social learning process that determines social behavior through observation learning and vicarious reinforcement (Bandura, 1977). The scholar revealed it is common that students construct ideas, the concept based on their social environment. Therefore, students excessively exposed to the effects of humanizing technology could socially learn aggressive behavior through observational learning and vicarious reinforcement. According to Bandura (1977) stated that used in psychology, education, and communication holds that components of an individual's knowledge acquisition can be immediately related to observing others within the setting of societal interactions, experiences, and outside media influences.

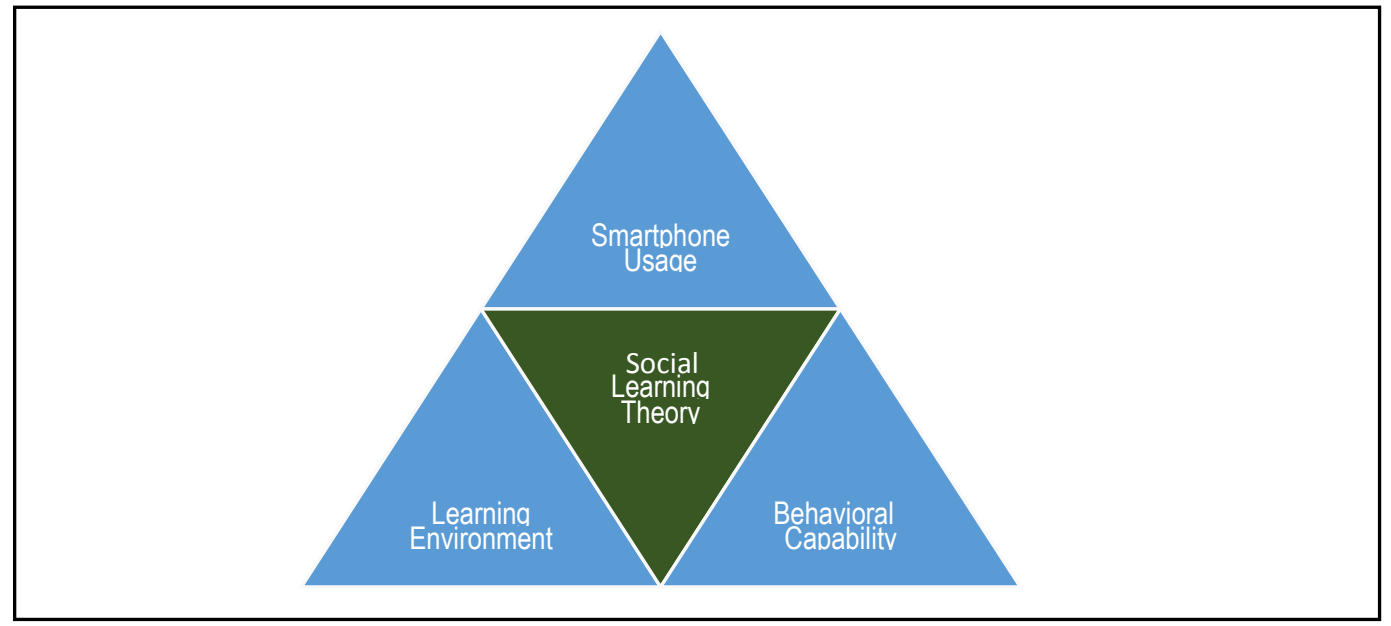

Fig. 1: Conceptual Framework Adapted from Social Learning Theory Bandura (1977)

\subsection{Methodology}

This study adopted the mixed-method approach. An explanatory mixed-method approach was utilized in this study, which began with the quantitative approach and then supported by the qualitative approach. According to Creswell and Clark (2018), the Explanatory Design, also known as the Explanatory Sequential Design, is suitable for educational research studies. Also, the design of this study is useful for explaining isolated cases, explaining whether the data is significant or not significant, and explaining the emergence of new data. Furthermore, this design is suitable for conducting a quantitative study and is followed by qualitative research. The design of this study is useful because the study can use the characteristics of the respondents from the quantitative findings to serve as a guide for selecting sampling is based on qualitative studies that to be carried out next step. Therefore, this study is appropriate using Explanatory Design based on the recommendation of Creswell and Clark (2018). Other studies used Explanatory Sequential Design to provide more comprehensive evidence to study the research problem instead of solely relying on quantitative or qualitative research (Arango-Morales, Delgado-Cruz, \& Tamayo-Salcedo, 2019; Siahaan, 2020). The scholars revealed that the scope is explanatory sequential design since it not only sought to relate the observed variables but also to explain why and in what conditions intended to help explain or elaborate the previously obtained quantitative results. First, for the quantitative, the questionnaires were distributed to the respondents consists of 150 secondary school students in Klang Valley based on Krejcie and Morgan (1970) sample size formula. The respondents were the secondary school students aged between 13-18 years and living in Klang Valley, Selangor, Malaysia. There was a completed selfadministered questionnaire consist of socio-demographic, behavioral responses, smartphone usage in the learning environment, and students' behavioural capability. The set of questions required the respondents to use the Likert scale with a range of 1 (strongly disagree) to 5 (strongly agree). In addition, the regression analysis is a set of statistical processes method applied in this study for estimating the relationships between the variable. This study also used process, developed by Hayes Model for moderating effect analysis. Second, for the qualitative approach, this study proposed sample sizes, often three or fewer participants. The interview questions are open-ended to permit the participants to distinguish their experiences. The thematic analysis is utilized as a part of subjective research and focuses on examining themes within the data. This method emphasizes the organization and rich depiction of 
the data set. The study uses the constant comparative method and utilizes the data from the interviews to corroborate the quantitative findings. The questionnaire for quantitative and qualitative adopt and modified from past research that is related to this study (Kwon, Kim, Cho, \& Yang, 2013; Billieux et al., 2015; Ifinedo, 2017; Kuss et al., 2018).

\subsection{Limitation of Study}

The limitation of the study is the lack of precedence and evidence of the use of smartphones in the learning environment at private schools. The non-significant result is probably due to the type of error or the small sample size of this study with 28 samples only. The sample size was only limited to secondary school students located in Klang Valley, Selangor, Malaysia, who received the questionnaire. Therefore, a larger sample size from private schools is required (e.g., learning experience) that would strengthen the research base.

\subsection{Findings}

A total number of 150 secondary school students located in Klang Valley participated in this study. The majority of the respondents are females (58.0\%). Respondents age $13-14$ years old are the majority $(35.0 \%)$, followed by $17-18$ years old $(30.0 \%), 15-16$ years old $(26.0 \%)$, and more than 19 years old $(18.7 \%)$. The majority of respondents who participated in this study are Malay (96.7\%), and the remaining were Chinese and others. Out of 150 respondents, 90 went to the public schools $(70.7 \%)$, followed by private schools $(18.7 \%)$, do not go to school (6.0\%), and those who were homeschooled (4.7\%). The findings of this study revealed that 123 respondents own a smartphones $(82.0 \%)$ and remaining is not have a smartphones. Also, the findings showed that smartphone usage for social networking was influenced by gender, where social factors influenced the female respondents as compared to male respondents. Moreover, (Instagram, Facebook, YouTube) has increased as the predominant social network for communication among female (see Table 1).

\begin{tabular}{|c|c|c|}
\hline Characteristics & Frequency & Percentage (\%) \\
\hline \multicolumn{3}{|l|}{ Gender } \\
\hline Male & 63 & 42.0 \\
\hline Female & 87 & 58.0 \\
\hline \multicolumn{3}{|l|}{ Age } \\
\hline $13-14$ years old & 53 & 35.3 \\
\hline $15-16$ years old & 39 & 26.0 \\
\hline $17-18$ years old & 45 & 30.0 \\
\hline 19 years old and above & 13 & 18.7 \\
\hline \multicolumn{3}{|l|}{ Race } \\
\hline Malay & 145 & 96.7 \\
\hline Indian & 2 & 1.3 \\
\hline Chinese & 2 & 1.3 \\
\hline Others & 1 & 0.7 \\
\hline \multicolumn{3}{|l|}{ Schools } \\
\hline Public Schools & 106 & 70.7 \\
\hline Private Schools & 28 & 18.7 \\
\hline Self-Learning & 7 & 4.7 \\
\hline Not to Schools & 9 & 6.0 \\
\hline \multicolumn{3}{|l|}{ Do you Own Smartphones } \\
\hline Yes & 123 & 82.0 \\
\hline No & 27 & 18.0 \\
\hline
\end{tabular}

\subsection{Profile of Respondents (Qualitative Approach - In-Depth Interviews)}

The purpose of in-depth interviews is to strengthen and support the findings obtained from the quantitative study. As a follow-up to the findings of the quantitative approach, this study further explores the perspective of smartphone usage in the learning environment from three respondents located in Klang Valley. The three respondents were among the key respondents that were identified from the survey, which represents the age range of 13,15 , and 17 years old. The presentation of qualitative findings is based on the thematic analysis derived from the feedback provided by the respondents. In this study, a pseudonym was applied to protect the confidentiality of the information given by the respondents. This study uses M1, M2 pseudonym for male respondents, and F1 for female respondents. Their level of education varies from UPSR, PT3, and SPM. The majority of the respondents that were interviewed are male (see Table 2). The findings revealed that there is a significant relationship with smartphone usage in the learning environment among respondents.

Table 2. Profile of Respondents (Qualitative Findings) $(\mathrm{N}=3)$

\begin{tabular}{llllll}
\hline Respondents & Age & Gender & Level education & Smartphone usage & $\begin{array}{l}\text { Learning environment experience } \\
\text { (apps) }\end{array}$ \\
\hline M1 & 17 & Male & SPM & Yes & Yes \\
\hline M2 & 15 & Male & PT3 & Yes & Yes \\
\hline F1 & 13 & Female & UPSR & Yes & Yes \\
\hline
\end{tabular}

In order to examine the behavioral responses on smartphone usage among students in the Klang Valley, multiple linear regression analysis was utilized. The general purpose of linear multiple regression analysis is to examine the relationship/influence of independent 
variables or predictors (learning environment) and a dependent variable or criterion variable (behavioral capability). All assumptions for multiple linear regression were met-data was normally distributed, linear, no multicollinearity issue $(T O L>0.3, V I F<4.0)$, and no autocorrelation issue (Durbin-Watson $=1.331$, between $1.5-2.5$ ). The findings of this study reveal that the behavioral responses on smartphone usage among students have a significant effect $(p<0.05, \beta=-.165)$ (see Table 3).

Table 3. Multiple Linear Regression analysis

\begin{tabular}{lccccc}
\hline & Beta & $\mathrm{t}$ & Sig. & Tol. & VIF \\
\hline (Constant) & & 13.134 & 0.00 & & \\
Learning_Env (IV) & -.165 & -2.033 & 0.44 & 1.000 & 1.000 \\
\hline
\end{tabular}

a. Dependent Variable: dv_behav

Furthermore, multiple linear regression analysis was utilized for examining the significant relationship between smartphone usage in the learning environment. The Durbin-Watson value should be between 0 until 4 with a value of 2 . The value of 2 indicates that there is no autocorrelation. However, if the value is greater than 2, it can be indicated that there is a negative correlation, but a positive correlation is implied if the value is less than 2 (Field, 2014). The value of Durbin-Watson derived from the findings of this study is 1.331 , which indicates no autocorrelation issue. This finding is supported by Field (2014) since the value is more than one and less than 3. Meanwhile, the value of ( $\mathrm{R}$ Square) amounted to .27, which is represented as $27.0 \%$. Overall, the variable indicates a positive correlation with no autocorrelation. Hence, there is no multicollinearity and autocorrelation issue in this study (see Table 4).

Table 4. Autocorrelation

\begin{tabular}{llllll}
\hline \multicolumn{5}{c}{ Table 4. Autocorrelation } \\
\hline Model & $\mathrm{R}$ & R Square & Adjusted R Square & Std. Error of the Estimate & Durbin-Watson \\
\hline 1 & $.165^{\mathrm{a}}$ & .027 & .021 & 3.18271 & 1.331 \\
& & & & & \\
\hline \multicolumn{5}{c}{ A. } & Predictors: (Constant), Learning Env
\end{tabular}

B. Dependent Variable: Behav_Capability

Process, developed by Hayes Model, is adopted in this study to examine whether the smartphone usage moderates the relationship between the learning environment and behavioral capability. In this study, the moderating variable is to analyze the relationship between independent variables, which is a learning environment that could affect behavioral capability. A moderator effect of some variables $\mathrm{F}$ on the outcome variable $Y$ is one in which its size or direction is dependent on the value of a third moderator variable $M$. Analytically, the moderated effects disclose the variable statistically as an interaction between $F$ and $M$ in a mathematical model of $Y$ (Hayes \& Matthes, 2009). According to the result, the $\mathrm{R}^{2}$ change value explains that the independent variable of the learning environment has a $12.54 \%$ relationship with the behavioral capability. Hence, this shows that the variable has a very significant effect because the $p$-value is less than 0.05 . The findings of PROCESS analysis reveal that smartphone usage moderates the relationship between the learning environment and behavioral capability among students (see Table 5).

Table 5. PROCESS analysis (moderating effects)
Outcome: Students Behavioural capability

\subsection{Discussion}

The findings of this study revealed that the behavioral responses on smartphone usage among students have a significant effect. The students who are equipped with self-regulated learning strategies would be more active in adopting a set of supportive online learning behaviors responses, such as creating a schedule, managing their time, communicating with teachers and classmates during their online course, knowing their resources, and having a dedicated study space. Accordingly, students, who have adopted more supportive online learning behaviors responded more confidently about their understanding of the subject matter and expect they will perform well in the classroom. Furthermore, there is a significant relationship on smartphone usage in the learning environment among respondents, where the majority of the students use smartphones as a tool for information seeking and can be accessed anytime and anywhere. The learning instruments and applications provided in smartphone assisted with their academic performance. This corroborates the findings from (Kumi Yeboah \& Smith, 2016; Redmond, Heffernan, Abawi, Brown, \& Henderson, 2018; Yeh et al., 2019). The findings from the analysis (quantitative and qualitative) showed that there are significant influences of deep, cognitive learning among the school students, which affected the behavioral capability. This study attempted to provide insights into the different drivers that could affect the behavior capability of the students in smartphone usage for educational purposes. In this study, $82 \%$ of the students own smartphones and use the device as a learning platform in virtual learning. The students showed active interest and learned new things quickly. The device could foster the behavior capability towards the use of smartphones for their curriculum, which was perceived as potential tools to enhance and improve the learning process. The e-learning software is designed to be user-friendly as well as to ensure independent learning. The different tools made learning more impactful and less time-consuming. This is also supported by the findings from (Redmond, Heffernan, Abawi, Brown, \& Henderson, 2018; Kacetl and Klimova, 2019). The key advantages for smartphone usage are confirmed with the following benefits: the enhancement of the learner's cognitive capacity, the learner's motivation to study in both formal 
and informal settings, the learner's autonomy and confidence, as well as the promotion of personalized learning, helping low-achieving students to reach their academic performance goals.

\subsection{Conclusion \& Recommendations}

By humanizing technology, theological considerations are set aside. For example, smartphone applications can be customized for the curriculum of the secondary school students. Using smartphones as an educational technology tool is a rational and logical way for educators to respond to various students' needs. From the result, humanizing technology allows for the shift from content delivery to identifying and addressing student needs. Also, usage of smartphones can create a safe environment for students to participate in class discussions, and to emphasize a reflective process into students' needs through personalization. Besides, the result showed that millennials are addicted to technology. Routing this addiction towards deep learning in the classroom would result in better student engagement. The result also shown that embracing and humanizing technology were crucial motivations for a successful provision of the level of care and individualized attention in the learning environment. The other phase is the extensive review highlights on humanizing technology in the learning environment. The study is significant as humanizing technology can allow educations to utilize the time and space in the classrooms fully as well as to get to know the student by increasing the level of compassionate teaching. The implications of humanizing technology are new approaches that can measure learning that lies outside of traditional assessment. By humanizing educational technology, the literature reviewed has demonstrated that smartphone usage has evidenced significant student engagement in the learning environment. The ripple effect of humanizing technology of smartphone usage is in the form of digital equity and digital democracy. The perception of smartphone usage in the learning environment, in turn, is interpreted as actual academic performance. Thus, if the school students are confident that they can perform positive behavioral capability, then it is more likely that they would display this behavior towards the desired outcomes. Smartphone usage in the learning environment is common, but these issues have received insufficient policy and scholarly attention in Malaysia. As a result of the study, the Ministry of Education should put in more effort and create a policy on smartphone usage among school students in the learning environment. This effort is particularly display by government in transformation education for a new impetus IR4.0 to align with the country's Shared Prosperity Vision 2030. In the context, it is vitally important to the students to appropriate their education to the future workforce. The results also showed that Malay students in public schools prefer to use the smartphone for educational purposes. It is recommended that for future research, the participants should include students from the private schools, and this will provide for a larger sample size.

\section{Acknowledgements}

The publication of the paper received partial funding from the Fundamental Research Grant Scheme (053/2017). The authors would like to acknowledge the Research \& Innovation Division, Universiti Teknologi MARA, Selangor Branch, and the Faculty of Education, Universiti Teknologi MARA, Selangor Branch, Malaysia. Special thanks to the teachers, students, and the students' families in the district of Klang for their participation in this study.

\section{References}

Alhassan, A. A., Alqadhib, E. M., Taha, N. W., Alahmari, R. A., Salam, M., \& Almutairi, A. F. (2018). The relationship between addiction to smartphone usage and depression among adults: a cross sectional study. BMC Psychiatry, 18(1), 148. https://doi.org/10.1186/s12888-018-1745-4

Anshari, M., Almunawar, M. N., Shahrill, M., Wicaksono, D. K., \& Huda, M. (2017). Smartphones usage in the classrooms: Learning aid or interference?. Education and Information Technologies, 22(6), 3063-3079.

Aljaloud, A., Billingsley, W., \& Kwan, P. (2019). Factors that influence teachers' decisions to use smartphone clicker apps to enhance teacher-student interactions in university classrooms in Saudi Arabia. Learning: Research and Practice, 5(1), 67-86. https://doi.org/10.1080/23735082.2018.1459802

Alghamdi, A., Karpinski, A. C., Lepp, A., \& Barkley, J. (2020). Online and face-to-face classroom multitasking and academic performance: Moderated mediation with selfefficacy for self-regulated learning and gender. Computers in Human Behavior, 102, 214-222. https://doi.org/10.1016/j.chb.2019.08.018

Arefin, S., Islam, R., Mustafi, M. A. A., Afrin, S., \& Islam, N. (2017). Impact of Smartphone Addiction on Business Students' Academic Performance: A Case Study. Independent Journal of Management \& Production, 8(3), 955. https://doi.org/10.14807/ijmp.v8i3.629

Arango-Morales, A. J., Delgado-Cruz, A., \& Tamayo-Salcedo, A. L. (2019). Digital Competence of Tourism Students: Explanatory Power of Professional Training. European Journal of Investigation in Health, Psychology and Education, 10(1), 310-326. https://doi.org/10.3390/ejihpe10010024

Bussell, H. (2019). Public Youth Librarians Use Technology in Ways that Align with Connected Learning Principles but Face Challenges with Implementation. Evidence Based Library and Information Practice, 14(3), 141-143. https://doi.org/10.18438/eblip29586

Bandura, A., \& Walters, R. H. (1977). Social learning theory (Vol. 1). Englewood Cliffs, NJ: Prentice-hall.

Bryant, B. R., Ok, M., Kang, E. Y., Kim, M. K., Lang, R., Bryant, D. P., \& Pfannestiel, K. (2015). Performance of Fourth-Grade Students with Learning Disabilities on Multiplication Facts Comparing Teacher-Mediated and Technology-Mediated Interventions: A Preliminary Investigation. Journal of Behavioral Education, 24(2), $255-272$. https://doi.org/10.1007/s10864-015-9218-z

Cha, S., \& Seo, B. (2018). Smartphone use and smartphone addiction in middle school students in Korea: Prevalence, social networking service, and game use. Health Psychology Open, 5(1), 205510291875504. https://doi.org/10.1177/2055102918755046 
C Chan, N. N., Walker, C., \& Gleaves, A. (2015). An exploration of students' lived experiences of using smartphones in diverse learning contexts using a hermeneutic phenomenological approach. Computers \& Education, 82, 96-106. https://doi.org/10.1016/j.compedu.2014.11.001

Chen, R.-S., \& Liu, I.-F. (2017). Using a Two-Stage System Evaluation Approach to Explore the New Adoption of an Information System in the Mobile Era. Journal of Educational Computing Research, 55(7), 996-1021. https://doi.org/10.1177/0735633117692102

Fernandez-Montalvo, J., Penalva-Velez, M. A., \& Irazabal, I. (2015). Internet Use Habits and Risk Behaviours in Preadolescence. Comunicar, $22(44), 113-121$. https://doi.org/10.3916/C44-2015-12

Field, A. (2014). Discovering Statistics Using IBM SPSS Statistics. And Sex and Drugs and Rock'n'Roll. Pflege, 27(6), 430-430. https://doi.org/10.1024/1012$5302 / a 000397$

Hayes, A. (2013). Introduction to mediation, moderation, and conditional process analysis (Methodology in the Social Sciences) (The Guilford Press, New York, NY). In New York, NY: Guilford. https://doi.org/978-1-60918-230-4

Haug, S., Castro, R. P., Kwon, M., Filler, A., Kowatsch, T., \& Schaub, M. P. (2015). Smartphone use and smartphone addiction among young people in Switzerland. Journal of Behavioral Addictions, 4(4), 299-307. https://doi.org/10.1556/2006.4.2015.037

Ifinedo, P. (2017). Examining students' intention to continue using blogs for learning: Perspectives from technology acceptance, motivational, and social-cognitive frameworks. Computers in Human Behavior, 72, 189-199. https://doi.org/10.1016/j.chb.2016.12.049

Joosten, T., Cusatis, R., \& Harness, L. (2019). A Cross-institutional Study of Instructional Characteristics and Student Outcomes: Are Quality Indicators of Online Courses Able to Predict Student Success? Online Learning, 23(4), 354-378. https://doi.org/10.24059/olj.v23i4.1432

Kwon, M., Kim, D.-J., Cho, H., \& Yang, S. (2013). The Smartphone Addiction Scale: Development and Validation of a Short Version for Adolescents. PLoS ONE, 8(12), e83558. https://doi.org/10.1371/journal.pone.0083558

Kuss, D., Harkin, L., Kanjo, E., \& Billieux, J. (2018). Problematic Smartphone Use: Investigating Contemporary Experiences Using a Convergent Design. International Journal of Environmental Research and Public Health, 15(1), 142. https://doi.org/10.3390/ijerph15010142

Kacetl, J., \& Klimova, B. (2019). Use of Smartphone Applications in English Language Learning-A Challenge for Foreign Language Education. Education Sciences, 9(3), 179. https://doi.org/10.3390/educsci9030179

Kumi Yeboah, A., \& Smith, P. (2016). Relationships Between Minority Students Online Learning Experiences and Academic Performance. Online Learning, $20(4)$, n4. https://doi.org/10.24059/olj.v20i4.577

Krejcie, R. V, \& Morgan, D. W. (1970). Determining Sample Size for Research Activities. Educational and Psychological Measurement, 30(3), 607-610. https://doi.org/10.1177/001316447003000308

Kırcaburun, K., Kokkinos, C. M., Demetrovics, Z., Király, O., Griffiths, M. D., \& Çolak, T. S. (2019). Problematic Online Behaviors among Adolescents and Emerging Adults: Associations between Cyberbullying Perpetration, Problematic Social Media Use, and Psychosocial Factors. International Journal of Mental Health and Addiction, 17(4), 891-908. https://doi.org/10.1007/s11469-018-9894-8

Lara, J. J. S., \& Magraner, F. F. (2017). The ICT and gamification: tools for improving motivation and learning at universities. Proceedings of the 3rd International Conference on Higher Education Advances, 1-8. https://doi.org/10.4995/HEAD17.2017.5286

Lee, H., Kim, J. W., \& Choi, T. Y. (2017). Risk Factors for Smartphone Addiction in Korean Adolescents: Smartphone Use Patterns. Journal of Korean Medical Science, 32(10), 1674. https://doi.org/10.3346/jkms.2017.32.10.1674

Rowsell, J., Burke, A., Flewitt, R., Liao, H.-T., Lin, A., Marsh, J., ... Wohlwend, K. (2016). Humanizing Digital Literacies: A Road Trip in Search of Wisdom and Insight. The Reading Teacher, 70(1), 121-129. https://doi.org/10.1002/trtr.1501

Razzaq, A., Samiha, Y. T., \& Anshari, M. (2018). Smartphone Habits and Behaviors in Supporting Students Self-Efficacy. International Journal of Emerging Technologies in Learning (IJET), 13(02), 94. https://doi.org/10.3991/ijet.v13i02.7685

Ramadiani, Azainil, Haryaka, U., Agus, F., \& Kridalaksana, A. H. (2017). User Satisfaction Model for e-Learning Using Smartphone. Procedia Computer Science, 116, 373-380. https://doi.org/10.1016/j.procs.2017.10.070

Redmond, P., Heffernan, A., Abawi, L., Brown, A., \& Henderson, R. (2018). An Online Engagement Framework for Higher Education. Online Learning, 22(1), $183-204$. https://doi.org/10.24059/olj.v22i1.1175

Rizki, M., Supriyati, Y., \& Akbar, M. (2020). Factors Affecting Lecturer Engagement in E-Learning Teaching Method. Proceedings of the 4th International Conference on Management, Economics and Business (ICMEB 2019), 120(Icmeb 2019), 206-211. https://doi.org/10.2991/aebmr.k.200205.038

Sundus, M. (2017). The Impact of using Gadgets on Children. Journal of Depression and Anxiety, 07(01), 1-3. https://doi.org/10.4172/2167-1044.1000296

Samaha, M., \& Hawi, N. S. (2016). Relationships among smartphone addiction, stress, academic performance, and satisfaction with life. Computers in Human Behavior, 57, 321-325. https://doi.org/10.1016/j.chb.2015.12.045

Siahaan, E. B. (2020). Students ' Perception of Edmodo use as a Learning Tool. Journal of English Teaching, 6(February), 12-23. https://doi.org/10.33541/jet.v6i1.1061

Thorpe, K., Hansen, J., Danby, S., Zaki, F. M., Grant, S., Houen, S., ... Given, L. M. (2015). Digital access to knowledge in the preschool classroom: Reports from Australia. Early Childhood Research Quarterly, 32, 174-182. https://doi.org/10.1016/j.ecresq.2015.04.001 
Tarhini, A., Hone, K., \& Liu, X. (2015). A cross-cultural examination of the impact of social, organisational and individual factors on educational technology acceptance between British and Lebanese university students. British Journal of Educational Technology, 46(4), 739-755. https://doi.org/10.1111/bjet.12169

Yeh, Y.-C., Kwok, O.-M., Chien, H.-Y., Sweany, N. W., Baek, E., \& McIntosh, W. (2019). How College Students' Achievement Goal Orientations Predict Their Expected Online Learning Outcome: The Mediation Roles of Self-Regulated Learning Strategies and Supportive Online Learning Behaviors. Online Learning, 23(4), 23-41. https://doi.org/10.24059/olj.v23i4.2076 